
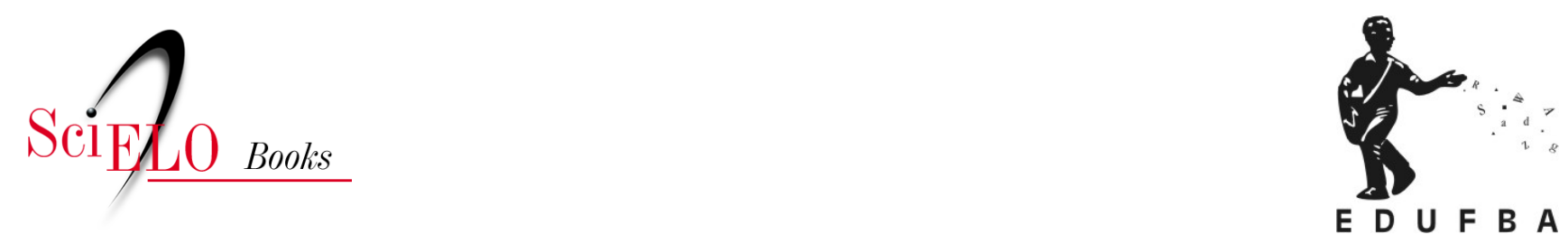

\title{
Percepção de riscos ocupacionais em catadores de materiais recicláveis
}

\author{
Denise Alves Miranda de Oliveira \\ Luiz Roberto Santos Moraes
}

\section{SciELO Books / SciELO Livros / SciELO Libros}

OLIVEIRA, D.A.M., and MORAES, L.R.S. Percepção de riscos ocupacionais em catadores de materiais recicláveis. In: FERNANDES, R.C.P., LIMA, M.A.G., and ARAÚJO, T.M., comps. Tópicos em saúde, ambiente e trabalho: um olhar ampliado [online]. Salvador: EDUFBA, 2014, pp. 77-102. ISBN: 978-655630-012-2. https://doi.org/10.7476/9786556300122.0006.

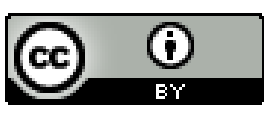

All the contents of this work, except where otherwise noted, is licensed under a Creative Commons Attribution 4.0 International license.

Todo o conteúdo deste trabalho, exceto quando houver ressalva, é publicado sob a licença Creative Commons Atribição 4.0. 


\section{Percepção de riscos ocupacionais em catadores de materiais recicláveis}

Denise Alves Miranda de Oliveira

Luiz Roberto Santos Moraes

\section{Introdução}

O advento da industrialização, dos aglomerados urbanos, a era dos descartáveis e a cultura do consumismo contribuem para gerar um grave problema ambiental e de saúde pública, causado pela grande quantidade de resíduos sólidos depositados na natureza, em quantidade e em composição, difíceis de serem decompostos pelo ambiente. Estes resíduos dispostos inadequadamente nos meios urbanos e rurais repercutem negativamente sobre a qualidade do meio, da vida e da saúde da população.

Há muito tempo, as civilizações já reconhecem os malefícios causados pelo descarte inadequado dos resíduos sólidos, a exemplo da poluição do solo, do subsolo, das águas superficiais e subterrâneas, do ar, do desmatamento, da obstrução de bueiros, das enchentes e dos desmoronamentos, e admitem também que são complexos os mecanismos viáveis para a resolução destes problemas. (OLIVEIRA, 2011)

Uma das alternativas no gerenciamento integrado dos resíduos sólidos urbanos é a coleta seletiva, a qual pode ser definida como um conjunto de procedimentos de recolhimento diferenciado dos resíduos sólidos que podem ser reutilizados ou reciclados. É uma atividade reconhecida como capaz de reduzir o descarte no meio ambiente dos materiais úteis que podem ser reintroduzidos no processo produtivo, contribuindo para a salubridade ambiental, o saneamento básico, a sustentabilidade urbana e a inclusão social com geração de trabalho, emprego e renda. (JACOBI, 2006) 
A coleta seletiva ganhou reconhecimento e está presente em muitos países, por contribuir para a promoção da educação ambiental voltada à diminuição do consumo, do desperdício, matéria orgânica, energia, na sustentabilidade urbana. Além destas questões ambientais, promove a valorização econômica dos materiais reutilizáveis e recicláveis, a geração de negócios, trabalho e renda, principalmente, para aqueles excluídos do mercado de trabalho formal. (SINGER, 2003)

A coleta seletiva insere-se com relevância estratégica no novo momento da economia mundial, caracterizado pelo respeito ao meio ambiente, pela participação da população e pela proposição de políticas de desenvolvimento sustentável. (JOIA; SILVA, 2004, p. 2)

Esta coleta consiste na separação e recolhimento dos resíduos sólidos descartados, segundo sua constituição ou características físicas, devendo ser iniciada na fonte geradora. Para que a coleta seletiva seja eficaz e eficiente, é necessário que a segregação dos materiais reutilizáveis ou recicláveis seja realizada por responsável pela geração dos resíduos sólidos.

A coleta seletiva possibilita à reutilização, a reciclagem, a substituição de matérias primas por outras que sejam mais adequadas à preservação do meio ambiente, reduzindo os impactos ambientais causados pela disposição inadequada de resíduos sólidos, uma vez que redireciona o que fazer com eles.

No Brasil, ainda são poucos os programas de coleta seletiva na fonte geradora, sendo esta atividade desenvolvida, principalmente, por catadores de materiais recicláveis. O trabalho realizado por estes trabalhadores consiste em catar, separar, transportar, acondicionar e, às vezes, beneficiar o material contido nos resíduos sólidos que tem valor de mercado e poderá ser vendido para reutilização ou reciclagem.

Atualmente, consideram-se catadores de materiais reutilizáveis e/ ou recicláveis as pessoas físicas de baixa renda que se dedicam às atividades de coleta, triagem, beneficiamento, processamento, transformação e comercialização de materiais reutilizáveis e recicláveis. (BRASIL, 2010)

Com o fim de contribuir com o conhecimento acerca desta nova modalidade de trabalho e acerca dos trabalhadores que o protagonizam, 
definiu-se pela realização de uma pesquisa qualitativa com catadores de materiais recicláveis em Salvador, Bahia.

A motivação pelo estudo do profissional catador de materiais recicláveis surgiu em uma reunião, com participação da comunidade da área de abrangência da Unidade de Saúde da Família, onde a primeira autora trabalhava. Quando no levantamento de problemas da área, o grupo apontou os catadores de materiais recicláveis como um "problema”, pois estes, durante sua atividade, rasgavam os sacos plásticos à procura de materiais recicláveis e deixavam os rejeitos dispostos nas calçadas das residências. Estes trabalhadores foram identificados, como integrantes de uma ONG de catadores, localizada próxima a Unidade de Saúde da Família, o que levou a primeira autora a refletir sobre o processo de trabalho dos catadores, os riscos à saúde aos quais estão diariamente expostos e sobre qual percepção de risco ocupacional apresentam estes catadores.

Esta pesquisa é justificada pela importância deste numeroso grupo social, constituído por idosos, homens, mulheres e crianças, os quais ainda são uma presença "invisível" constante nas ruas brasileiras, investidos da luta pela sobrevivência, em busca de inclusão e inserção no campo do labor. Além disso, os catadores de materiais recicláveis trazem à sociedade uma valorosa contribuição ambiental e para a saúde pública, resultante do fruto deste trabalho em estruturação e processo de desenvolvimento.

A pesquisa teve como objetivo analisar a percepção de riscos ocupacionais de catadores de materiais recicláveis de uma cooperativa no município de Salvador, Bahia.

\section{Percurso metodológico}

A pesquisa adotou como base científica uma metodologia qualitativa com o objetivo de descrever a percepção de riscos ocupacionais do grupo de catadores de materiais recicláveis de uma cooperativa em Salvador, Bahia, considerando a potencialidade desta ferramenta para a compreensão das dinâmicas sociais e formas de reflexão estabelecidas pelo grupo.

A definição do campo de pesquisa contemplou a escolha do espaço, do grupo de participantes, o estabelecimento de critérios para a seleção 
da cooperativa e de estratégia para a entrada em campo. Priorizou-se a cooperativa que, além de disponibilidade e interesse, os cooperativados exercessem atividade de coleta no território da rua.

O estudo foi realizado em 2010 com a participação de um grupo de catadores de materiais recicláveis, trabalhadores de uma cooperativa situada no Subúrbio Ferroviário de Salvador, Bahia.

Os participantes do estudo, representados pela totalidade dos cooperativados, formam um grupo de cinco homens e cinco mulheres, com idade entre 18 e 59 anos, com uma média de 38,5 anos, e escolaridade variando de $1^{\circ}$ grau a $2^{\circ}$ grau completo, com uma média de oito anos de escolarização.

Os sujeitos convidados concordaram em participar voluntariamente da pesquisa, sendo respeitados os seguintes critérios de inclusão: serem integrantes da Cooperativa em questão, serem maiores de 18 anos, incluindo homens e mulheres.

Iniciou-se o trabalho de campo com a técnica da observação participante. A escolha das situações de observação visava à abrangência do cotidiano e rotina das atividades. As visitas da primeira autora ao campo ocorreram em média três vezes por semana, durante o turno matutino, estendendo-se até o final das atividades dos cooperativados.

A observação foi realizada em três ambientes: 1. O galpão, sede da Cooperativa, imóvel de um único cômodo para a realização de todas as atividades, desde as administrativas até a seleção, separação e armazenamento do material. Neste espaço os catadores permanecem realizando triagem e armazenamento do material; 2. O Condomínio Parque Empresarial da Lagoa (Complexo de Fábricas - denominação utilizada pelos catadores de materiais recicláveis - assim denominado na pesquisa). É uma área de $130.000 \mathrm{~m}^{2}$ onde funcionam 20 galpões de indústrias de diversos segmentos de atividade econômica, entre essas, indústrias de: móveis de madeira e metal, tapetes, vestuário, embalagens, papel higiênico e alimentos. Localiza-se próximo ao galpão da Cooperativa e é considerado o grande doador de materiais recicláveis; 3. O percurso entre o Condomínio Parque Empresarial da Lagoa e a sede da Cooperativa, trecho com pavimentação precária, declives, solo irregular e trânsito movimentado.

As anotações consideradas importantes para a análise das entrevistas como informações sobre conversas, atitudes, expressões, 
relacionamentos, tomada de decisões, comportamentos, gestos, contexto histórico, situações reais, interferências, pausas, comentários, ou seja, as demonstrações que se referiram ao tema estudado foram registradas em Diário de Campo.

Após conhecido o processo de trabalho por meio da observação e estreitamento do respeito e confiança, iniciou-se a técnica da entrevista individual, sendo aplicado um roteiro de entrevista semiestruturado. O roteiro para efeito de análise foi dividido em quatro seções, contemplando perguntas sobre: a. identificação; b. história profissional; c. levantamento de noções sobre risco, segurança e saúde; d. percepção de risco. A partir desse instrumento, objetivou-se construir um perfil socioeconômico, de saúde e ocupacional do grupo, identificar o processo de trabalho e conhecer a percepção dos riscos ocupacionais.

A técnica da entrevista, de natureza individual, permitiu a obtenção de dados subjetivos relacionados às atividades de trabalho, experiências, sentidos, significados, valores, crenças, apreciações e costumes dos sujeitos entrevistados, e a técnica de observação participante permitiu observar fenômenos que não são obtidos por meio da entrevista. (CRUZ et al., 2002)

As entrevistas foram gravadas, com auxílio de gravador de voz, para posteriores transcrições das falas na íntegra e análise dos discursos. Aconteceram no galpão da Cooperativa, durante o turno de trabalho.

A análise dos dados foi feita com base nos preceitos da Análise do Discurso, visando realizar uma apreensão das condições de produção e significação de textos, inferindo a partir da linguagem e sua organização os processos de sua construção. (MINAYO, 2007)

Assim, o estudo discursivo, em suas análises, considera não apenas o que é dito, mas o que já foi dito e até mesmo o não dito, atentando, também, para a posição social e histórica dos sujeitos e para as formações discursivas às quais se filiam os discursos. (FRASSON, 2007) Os princípios e os procedimentos analíticos da análise de discurso podem situar melhor o indivíduo com a linguagem, o mundo, os outros sujeitos, os sentidos e com a história. (ORLANDI, 2009)

O texto oriundo das entrevistas foi submetido a várias operações classificatórias: decompor cada frase em proposições, restabelecer a ordem corrente na frase, reagrupar os termos de ligação, refazendo o discurso, buscando as dependências funcionais da linguagem evidenciada 
na frase. E há vários procedimentos como: proceder ao estudo das palavras do texto; separar os termos constituintes, analisar os adjetivos, os substantivos, os verbos e os advérbios; realizar a análise da construção das frases, construir uma rede semântica entre o social e o gramatical e elaborar a análise, considerando a produção social do texto como constitutiva do seu próprio sentido. (MINAYO, 2007)

A análise das entrevistas foi enriquecida pelo poder da observação participante na subjetividade dos personagens, na fala, nos detalhes dos gestos e expressões dos trabalhadores no local da pesquisa.

Os aspectos éticos foram contemplados em conformidade com a Resolução n 196/1996 do Conselho Nacional de Saúde (CNS), referente aos aspectos para pesquisa com seres humanos. (BRASIL, 1996)

\section{O ingresso de catadores de materiais recicláveis na cooperativa}

A Cooperativa de catadores de materiais recicláveis estudada nesta pesquisa foi implantada como uma estratégia que trouxesse emprego e renda para os moradores do bairro. Durante este processo, o grupo enfrentou diversos entraves como falta de treinamento em segurança no trabalho, dificuldade de acesso a equipamentos como carrinho para coleta e transporte de materiais e ao galpão para triagem e armazenagem do montante coletado.

Posteriormente, com o intuito de aumentar a renda, os integrantes da referida cooperativa começaram a executar um trabalho paralelo junto a um atravessador, período em que o grupo de cooperativados era responsável por realizar apenas a triagem do material. Nas horas livres, continuavam a coletar porta-a-porta o material para a Cooperativa.

Neste grupo, as ocupações anteriores à atividade com coleta de materiais recicláveis referiam-se a atividades do setor terciário, principalmente vinculadas ao comércio, trabalho doméstico, prestação de serviços, sempre ligadas ao mercado informal. O grupo de trabalhadores de 18 a 20 anos teve experiência com trabalhos de gesseiro, ajudante de pedreiro, vendedor de água envasada, garçom, manicure, estágio para Menor Aprendiz no Centro Administrativo da Bahia (CAB) e os sujeitos acima de 47 anos já trabalharam como costureira, cozinheira, 
doceira, lavadeira de roupas, construção civil, soldador, babá, empregos domésticos, serviços gerais e venda de temperos.

A situação de desemprego vivenciada pelas catadoras deste grupo, antes da inserção na Cooperativa, apareceu como precursora de depressão. A inserção no mercado de trabalho promovida pela atividade de coleta de material reciclável é trazida como fundamental para o redirecionamento de suas vidas. Para elas, esta ocupação ocasiona prazer, alegria, bem estar, formação de vínculos de amizade, poder aquisitivo e satisfação pessoal.

Para os catadores com idade maior do que 47 anos, permanecer na Cooperativa é uma opção. Demonstram paixão pela atividade. Eles fazem parte da história de luta da Cooperativa. Existe o sentimento de pertença e de valor. Portanto, cada dia de trabalho traz satisfação, alegria, diversão, sensação de dever cumprido. A satisfação pessoal pelo trabalho de catador entre aqueles com idade mais avançada também foi encontrada no estudo de Almeida, Elias, Magalhães (2009).

Pressupõe que esta elevada satisfação referida, diminua a percepção de risco. Por se tratar de uma atividade prazerosa, o risco fica oculto.

Entre os catadores mais jovens, aqueles com idade entre 18 e 20 anos, o trabalho na Cooperativa representa uma experiência passageira, pois a sua pretensão é a de que sua permanência na Cooperativa seja provisória. Esta ocupação é sinônimo de ajuda, forma de ocupar o tempo de uma maneira produtiva e de gerar renda. O tempo médio de experiência com a coleta seletiva é de 2,4 anos, ao passo que entre os que têm acima de 47 anos este tempo é de 7,8 anos.

Estes catadores de materiais recicláveis têm a coleta seletiva como principal fonte de renda, além do benefício social do programa Bolsa Família, recebido por cinco membros do grupo. O rendimento mensal varia de $\mathrm{R} \$ 100,00$ (cem reais) a $\mathrm{R} \$ 150,00$ (cento e cinquenta reais) e é variável de acordo com a quantidade de materiais coletados a cada mês.

O Brasil tem vivenciado, principalmente na década de 90, transições nos setores econômico, social, demográfico e tecnológico que atingem diretamente o mercado de trabalho, a dinâmica e as estruturas setoriais e ocupacionais. Como exemplo disso, tem-se o desemprego, o surgimento de novas formas de contratação, o trabalho informal, a flexibilidade nas relações de emprego, a abertura comercial e a reforma do papel do Estado. (NAVARRO, 2007) Mesmo com o incremento 
ocorrido no emprego nos últimos dez anos, as formas alternativas e muitas vezes precárias de trabalho não foram superadas.

Nos contextos capitalistas, o emprego configura uma atividade humana, visa à manutenção e à sobrevivência da espécie, aquisição de bens, prazer, satisfação e realização pessoal, aceitabilidade social, promoção das relações interpessoais, inspiração, desenvolvimento da autonomia e criatividade. Estabelece sentimento de inclusão, integração e convívio social, de respeitabilidade, de pertença, de contentamento, estruturador de identidade pessoal e profissional. (OLIVEIRA, 2011)

A inserção dos trabalhadores estudados na atividade de coleta de material reciclável pode refletir a insuficiente oferta de empregos formalizados no Brasil, mesmo considerando o incremento do emprego já referido. Neste cenário, os trabalhadores têm procurado novos mecanismos capazes de garantir a geração de renda e o suprimento de suas necessidades básicas. Dessa forma, a coleta seletiva de materiais reutilizáveis e/ou recicláveis pode ser considerada uma oportunidade que viabiliza a inclusão no mundo do trabalho. Ainda que não garanta direitos sociais e trabalhistas, tais como os sistemas de proteção a trabalhadores que adoecem ou se acidentam no trabalho, a coleta seletiva ganha importância e vem crescendo continuamente. Representa uma possibilidade de inserção no mundo social e do trabalho, gera renda e trabalho para homens e mulheres que, por meio desta atividade, garantem a sua subsistência. (OLIVEIRA, 2011)

O ingresso no trabalho com os resíduos sólidos se dá, em grande parte, pela baixa escolaridade (que dificulta a conquista de outras profissões melhor remuneradas), crise econômica, desemprego e necessidade de ajudar nas despesas do lar, como meio de sobrevivência e independência, forma de fazer amigos, integração no mercado de trabalho, de sentir-se útil e produtivo. Porém, esta modalidade de trabalho não deixa de ter a conotação negativa construída socialmente em torno dos resíduos sólidos, ou seja, daquilo que é jogado fora, que gera asco, discriminação e preconceito. (MEDEIROS; MACEDO, 2006)

Normalmente, os trabalhadores de materiais reutilizáveis e/ou recicláveis aderem a esta atividade devido à exclusão do mercado formal de trabalho. Para os trabalhadores do presente estudo, antes de iniciarem a atividade como catadores, muitos, já tinham tido outras experiências em diferentes ramos produtivos. Estudo de Medeiros e Macedo 
(2006) cita experiências profissionais anteriores de trabalhadores que coletam materiais recicláveis como mecânicos, lanterneiros, pedreiros, pintores, pescadores, cozinheiras, costureiras, vigilantes, auxiliares de protéticos, balconistas e artistas plásticos.

Nesta conjuntura de ainda desemprego, informalidade, precarização das relações de trabalho, desigualdades sociais, pobreza, forma de consumo instituída e geração de grandes quantidades de resíduos sólidos, a atividade de coleta seletiva desenvolvida pelos catadores de materiais recicláveis surge como possibilidade de sustento. Acrescido das discussões ecológicas, ganha relevância ambiental e econômica, mas continua a se relacionar com um fenômeno de exclusão social instalado na sociedade. (SIQUEIRA; MORAES, 2009)

\section{Catador de materiais recicláveis, cotidiano e risco}

O cotidiano de trabalho dos sujeitos cooperativados deste estudo consiste em coleta manual de resíduos sólidos, carregamento e descarregamento do caminhão nos momentos de venda e recebimento de material doado, reparos e condução dos carrinhos de coleta, compactação da carga no interior do carrinho de coleta, triagem por composição, limpeza, armazenamento, distribuição e venda.

Costumam trabalhar oito horas por dia, mas a jornada de trabalho está mais relacionada à quantidade de trabalho do que ao cumprimento de uma carga horária fixa. Em dias de menor carga de trabalho, são liberados após a finalização das tarefas. Não costumam apresentar absenteísmo no trabalho, e, quando o fazem, isso se dá apenas por causas relacionadas à saúde.

Os riscos mais citados são a presença de materiais perfurantes e cortantes nos resíduos coletados, os riscos relacionados ao manuseio de carga, ou seja, ao trabalho físico pesado, com uso de força e posturas anômalas do corpo, de acidentes como quedas e acidentes de trânsito, manuseio de substâncias irritantes como pós e produtos químicos e a informalidade.

Principal personagem da coleta seletiva, o catador de material reciclável, enfrenta ambiente e condições precárias de trabalho. Embora 
desenvolva uma atividade de importância ambiental, depara-se com adversidades no seu ambiente de trabalho, informalidade, violência, invisibilidade, exclusão social, discriminação e exposição a riscos.

Além dos catadores de materiais recicláveis autônomos caminhando diariamente pelas ruas com pesados fardos sob a cabeça e ombros, ou empurrando seus carrinhos, associações e cooperativas de catadores de materiais recicláveis também agem nesta atividade de forma mais organizada e em parcerias. As cooperativas atuando organizadas no processo de coleta seletiva visam gerar trabalho, renda, inclusão social, ações de educação ambiental, segurança no trabalho, capacitação, formação, cooperação técnica e financeira, divulgação e valorização da atividade de catação e aumento da quantidade e qualidade dos materiais coletados para maior poder de negociação, preços e competitividade.

Segundo Oliveira (2011), a ocupação do catador é marcada por precárias condições de trabalho, exposição a riscos, insalubridade, má remuneração, menosprezo, preconceitos e ausência de garantias trabalhistas que os defendam, principalmente, em condições de acidentes de trabalho, doenças, aposentadoria, décimo terceiro salário e seguro desemprego. As situações são tão adversas que contribuem para que a identidade profissional dos catadores seja assinalada pela exclusão social.

Os catadores de materiais recicláveis tiveram sua profissão regulamentada em 2002, com o registro na Classificação Brasileira de Ocupações (CBO) sob o número 5192-05. No rol das suas atribuições, consta a função de catar, selecionar e vender materiais recicláveis como papel, papelão e vidro, bem como materiais ferrosos e não ferrosos e outros materiais reaproveitáveis ou recicláveis.

A CBO de 2002 define que o trabalhador é exposto às variações climáticas, aos riscos de acidentes de trânsito, contaminações e cortes na manipulação do material e à violência urbana. (BRASIL, 2002)

O trabalho com materiais recicláveis é reconhecido como atividade que interfere diretamente no processo saúde/doença dos trabalhadores. Tem o potencial de trazer danos a sua saúde, pois estes podem adoecer ou morrer por consequência da profissão ou condições adversas em que seu trabalho é ou foi realizado. (FERREIRA; ANJOS, 2001)

Os principais riscos citados pelos trabalhadores estudados são os mesmos descritos na literatura e bem definidos por diversos estudos da 
área. (PORTO et al., 2004; VELLOSO; SANTOS; ANJOS, 1997; GONÇALVES, 2005) Os agentes frequentemente presentes nos resíduos sólidos são os de ordem física como: poeiras, ruídos excessivos, frio, calor, fumaça; químicos como líquidos que vazam de pilhas e baterias, óleos e graxas, pesticidas, herbicidas, solventes, tintas, produtos de limpeza, cosméticos, remédios, aerossóis, metais pesados como chumbo, cádmio e mercúrio; agentes biológicos, tais como microrganismos patogênicos: vírus, bactérias e fungos; riscos de acidentes com materiais perfurocortantes, com vidros, lascas de madeira, objetos pontiagudos; uso de força, posturas inadequadas, vibração e levantamento manual de peso. Os acidentes e doenças neste tipo de atividade geralmente acontecem em decorrência da precarização e falta de condições adequadas de trabalho. (FERREIRA; ANJOS, 2001)

Os ambientes e condições insalubres de trabalho são os principais responsáveis pela incidência, cada vez maior, de doenças ocupacionais entre os trabalhadores da coleta de materiais recicláveis. Mas, vale ressaltar que a exposição do indivíduo a situações que podem ocasionar acidentes e lesões sofre interferência do contexto, do comportamento e das medidas de prevenção tomadas. A percepção do risco, a sensação e condições de segurança, a autogestão e o conhecimento também podem influenciar nas ações de controle adotadas pelos trabalhadores.

\section{Risco ocupacional dos catadores da cooperativa}

No presente estudo, os catadores relatam não se preocuparem com o risco decorrente da manipulação dos resíduos descartados nos contenedores do Complexo de Fábricas por não conhecerem exatamente o que manipulam durante a coleta dos materiais. O reconhecimento da exposição à determinada substância presente nos resíduos sólidos como um fator de risco, só é feito, na maioria das vezes, depois de contato físico com repercussões negativas sobre o corpo.

Portanto, são o cotidiano do trabalho, as experiências pessoais ou alheias, as histórias de acidentes e incidentes passados pelos mais experientes que norteiam o comportamento de exposição. À medida que o trabalhador manuseia o resíduo sólido, começa a conhecer as características que determinam seu risco. São características físicas como 
aspecto, textura, cheiro e cor que passam a condicionar a exposição ou não do cooperativado a determinadas situações.

O desconhecimento dos catadores sobre o potencial de dano dos produtos encontrados e coletados favorece uma abordagem pouco segura. Possivelmente, o contato com os resíduos desconhecidos, não desperta nos catadores o temor e a preocupação com as repercussões sobre a saúde que justifiquem a sua não exposição. A aquisição do material reciclável, objeto de interesse dos trabalhadores que gera ganhos financeiros, parece exigir atenção superior à preocupação com a existência de riscos que podem ocorrer com o manuseio dos materiais desconhecidos.

Normalmente, o grupo não costuma apresentar cautela diante de conjunturas nunca antes vivenciadas, sejam estas circunstâncias ou exposições a resíduos sólidos, por não imaginá-las como uma situação potencial de risco.

O desconhecimento dos catadores de materiais recicláveis sobre os resíduos manipulados aumenta a vulnerabilidade, os acidentes e as doenças ocupacionais.

No entanto, nas ocasiões, durante a coleta de materiais recicláveis, onde o advento adverso, ou seja, o risco eminente já é conhecido, os catadores assumem uma postura preventiva, cautelosa, precavida antes do enfrentamento das situações. Assim sendo, mesmo diante da percepção e constatação do risco, a ocasião é enfrentada.

Portanto, a presença do risco pode ser desconsiderada neste contexto que relaciona lucro à quantidade de materiais coletados. Por mais perigosa que represente a circunstância, se gerar possibilidade de venda do material, é tida como parte do processo, e tolerada. Apenas quando a situação de perigo é interpretada como superior ao benefício trazido pela coleta, o comportamento é o do não enfrentamento, ou seja, de evitar a exposição.

Nessas situações percebidas como de risco, utilizam alternativas que buscam proteção e minimização, a exemplo da realização de movimentos menos bruscos no intuito de proteger-se, diminuindo a dispersão de pós. Reconhece-se também a naturalização na manipulação das substâncias contidas nos contenedores.

Neste contexto de incertezas, de desigualdades e de exposição a riscos enfrentados diariamente pelos catadores de materiais recicláveis, 
a percepção de risco ocupacional implica em desvelar os significados inerentes à percepção do indivíduo frente às situações corriqueiras de trabalho.

A exposição e vulnerabilidade individual do trabalhador a situações de risco estão vinculadas a condições cognitivas, econômicas, políticas, de poder, comportamentais, situacionais e sociais. (AYRES et al., 1999)

Outro fator que está relacionado à aceitabilidade do risco é o benefício advindo desta exposição. A abordagem do risco é complexa, envolve percepção, confiança no sistema regulador e quando os benefícios para determinado grupo são considerados superiores aos prejuízos, a tendência é a minimização e aceitação dos riscos. (NAVARRO, 2007; SANTOS, 1990; FERREIRA; ANJOS, 2001)

Assim, os experimentos vivenciados no passado interferem sobre a percepção do risco, principalmente em tarefas cotidianas, determinando o conceito pessoal de risco. (SANDERS; McCORMICK, 1993; JASANOFF, 1998; NOYES, 2001; MORAES et al., 2002)

Normalmente, o trabalhador quando nega o risco, o faz, como estratégia defensiva, devido ao enfrentamento constante de situações de perigo e termina por elaborar estratégias cognitivas de minimização do risco. (LIMA, 1998)

A aceitação e a minimização dos riscos pelos catadores de materiais recicláveis podem favorecer o aumento do número de acidentes e doenças ocupacionais. Para uma atitude preventiva é interessante que o trabalhador detecte, decifre e torne o risco significativo. Se o risco não é identificado, o trabalhador pode não assumir uma postura defensiva como a situação exige.

A perspectiva da inter-relação entre pessoa e ambiente naturaliza a abordagem do risco como se o enfrentamento fosse algo inerente à atividade, parecendo tornar invisível e insignificante o potencial de risco para o catador de materiais recicláveis. O valor, importante na caracterização do risco, é atribuído ao material reciclável e não à fonte potencial de dano. 


\section{Processo de trabalho, ambientes e percepção de risco}

Observou-se que a percepção de risco dos cooperativados sofre influência do espaço físico (sede da Cooperativa, Complexo de Fábricas ou percurso entre estes), condições e processo de trabalho realizado. E no enfrentamento dos riscos verificaram-se as variáveis gênero e tempo de serviço como determinantes na divisão de tarefas consideradas de risco pelos cooperativados do estudo.

As reproduções sociais definem as relações de gênero construídas dentro da organização da cooperativa pesquisada. Percebeu-se a existência de diferenciação entre homens e mulheres quanto à distribuição de tarefas. Trazem o mote de trabalho masculino e feminino. A atividade de coleta no Complexo de Fábricas, o manuseio do carrinho de transporte, a compactação da carga em cima do carro de transporte e as atividades consideradas mais penosas ficam a cargo dos homens.

$\mathrm{Na}$ avaliação do processo de trabalho, algumas atividades consideradas penosas, que precisam necessariamente ser realizadas fora do espaço da sede da Cooperativa, são delegadas aos homens, enquanto as mulheres permanecem no espaço da Cooperativa. É como se o homem exercesse o papel do "provedor" e a mulher da "cuidadora".

No concernente a gênero, Poeschl (2003), em seu estudo sobre as representações das diferenças entre os sexos, conclui que existe uma reprodução social das relações assimétricas entre os sexos na sociedade. Esta reprodução define atividades específicas, destinadas aos homens e às mulheres, que são perpetuadas na vida cultural cotidiana e interferem na tomada de decisões e posicionamento frente às situações diárias.

Esta representação da força masculina é mais frequente nos discursos femininos das cooperativadas com maior tempo de serviço e é bem aceita pelos sujeitos masculinos, que sendo mais jovens, assumem a responsabilidade por tais tarefas. Pressupõe-se que os fatores idade e respeito à determinação da execução das tarefas sejam determinantes na aceitação da exposição a tais situações, caracterizadas pelo grupo, como as mais perigosas.

A divisão de tarefas também é definida a partir do tempo de experiência com coleta seletiva, que é fator predisponente à exposição a 
situações consideradas como risco pelo grupo. Enquanto o cooperativado vai adquirindo experiência, ele permanece no espaço do galpão da sede da Cooperativa, considerado seguro. As tarefas intituladas como perigosas, a exemplo da coleta no Complexo de Fábricas, são executadas pelos mais experientes. Os novatos são poupados da exposição das tarefas vistas como perigosas, como um movimento de proteção e prevenção de acidentes.

Relativo aos ambientes de trabalho caracterizados pelos sujeitos da pesquisa como Complexo de Fábricas, percurso entre o Complexo de Fábricas e a sede da Cooperativa, estes possuem características e percepção de riscos ora distintas, ora comuns.

Vale ressaltar que, para os catadores de materiais recicláveis, o seu trabalho não tem uma única representação ou sentido, ele é ambíguo, refletindo a dialética saúde/doença, limpeza/sujeira, controle/vulnerabilidade, aceitação/negação, medo/segurança.

No ambiente do Complexo de Fábricas os catadores se referem a possibilidade de exposição a substâncias como: pós de alumínio, de serra e de vidro (das indústrias de móveis), tinta, solvente (principalmente das indústrias de vestuário), alimentos deteriorados (do restaurante), a cortes, a acidentes perfurocortantes, a quedas e a levantamento manual de peso.

Em relação às substâncias em pó reconhecidas como um risco, os catadores costumam fazer uma escala de perigo da exposição a partir da natureza do pó. Avaliam o risco à saúde, quantificando o volume e a natureza do pó existente dentro dos contenedores de onde retiram os materiais reutilizáveis e/ou recicláveis como papelões. O conhecimento sobre o assunto construído a partir das interpretações das informações disponíveis auxilia o grupo na tomada de decisões e na avaliação do risco-benefício.

Em relação à tarefa de compactação da carga durante a coleta de materiais, esta é considerada uma atividade eminentemente masculina. Os trabalhadores temem risco de queda e possibilidade do carrinho virar durante sua execução. Reconhecem nesta tarefa a necessidade de habilidades como agilidade, coragem e força, características, para o grupo, típicas dos homens, reforçando que as atividades reconhecidas como risco são delegadas à população jovem e masculina. Subentende-se que este subgrupo é capaz de superar as atividades que requerem 
mais força e de sair ileso das circunstâncias quando exposto a diferentes situações de risco.

Sobre a prática da compactação da carga e a presença de materiais ferrosos coletados e depositados no interior do carrinho de coleta, o catador não reconhece como um risco, pois o costume de colocá-los num canto do mesmo parece ser suficiente para evitar acidentes durante esta prática.

O risco associado à presença de materiais perfurocortantes durante o manuseio com o resíduo está presente no discurso de todos os cooperativados. Os trabalhadores reconhecem que os principais riscos ocupacionais são os acidentes com materiais perfurocortantes. A presença do objeto perfurocortante no resíduo sólido manipulado é tida como sinônimo de risco.

Portanto, os materiais cortantes e perfurantes são, naturalmente, representados e percebidos como risco, porém não foi observado temor a tais exposições. Para o grupo, a presença desses materiais é inerente aos resíduos sólidos e, portanto, a sua profissão, restando aos catadores utilizarem estratégias para a prevenção de acidentes como uso de luvas e sendo a manipulação realizada com cautela e atenção.

A percepção de risco ocupacional relacionado à presença de materiais perfurocortantes é comum nos estudos com catadores de materiais recicláveis. (VELLOSO; SANTOS; ANJOS, 1997) Assim também, é comum o relato de acidentes por tais materiais.

No percurso entre o Complexo de Fábricas e a sede da Cooperativa os catadores caracterizam a caminhada com os resíduos sólidos, no carrinho de transporte, como atividade difícil, perigosa, cansativa, com risco de atropelamento, de quedas, do carro de transporte virar, de manuseio de peso, de exposição ao sol e necessidade de percorrer longa caminhada.

A altura da carga que causa dificuldade de visibilidade, a instabilidade e o peso do carrinho adicionado ao da carga coletada, o trânsito movimentado, o peso da carga, as condições de má conservação dos carrinhos e as características do trajeto durante a condução dos materiais são relatadas como causas dos incidentes e acidentes no trajeto com os materiais coletados. O grupo considera não ter governabilidade sobre estes problemas, o que aumenta sua vulnerabilidade. 
O grupo demonstra um sentimento ambíguo em relação ao carrinho de coleta. O reconhecem como um instrumento de trabalho facilitador, importante e vital, mas, também como sinônimo de peso, risco, instabilidade, dificuldade, sobrecarga e cansaço.

Compreende-se que a percepção de risco do grupo sobre a condução do carrinho de coleta como um evento de risco, sendo necessárias desenvolturas para a sua realização. Mesmo diante da percepção de risco, o grupo não relaciona insatisfação ou medo, costuma naturalizar tais exposições como inerentes ao processo e como próprio da sua atividade enquanto catador de materiais recicláveis.

No concernente à sede da Cooperativa, esta é caracterizada pelo grupo como extensão da casa, ambiente de trabalho harmonioso, seguro e limpo. A sede foi resultado de conquista, luta, portanto há um sentimento de posse, de lar, de aconchego. Na sede, trabalham pessoas com vínculos familiares e afetivos sólidos, que se preocupam umas com as outras, não há chefes, apenas amigos e relações de autonomia, o que permite considerar que a sede da Cooperativa é percebida como um fator de proteção.

Após uma primeira triagem realizada ainda no Complexo de Fábricas, os resíduos sólidos parecem perder o potencial de risco ao chegarem à sede da Cooperativa. É como se já fossem conhecidos e inofensivos. Como se o ambiente da sede da Cooperativa e o grupo de cooperativados promovessem uma segurança. As práticas que justificam esta conclusão são a rejeição do uso da luva na sede, usando-a exclusivamente no território da rua, e os discursos de que a sede é limpa, rejeitando a conotação de sujeira e risco e da comparação do galpão a uma atmosfera de lar, culturalmente associado à segurança. É como se o território da rua oferecesse riscos de contaminação e o da sede da Cooperativa não.

A partir dos discursos dos catadores observou-se que o ambiente físico da sede da Cooperativa é considerado como um espaço seguro e livre da exposição ao risco comparado as suas casas. Esta ideia é difundida pelos catadores com maior tempo de permanência na Cooperativa.

Em relação aos riscos associados ao manuseio de carga, posturas anômalas e uso de força, eles são representados apenas quando relacionados à coleta de materiais recicláveis, à condução do carinho de transporte e ao levantamento dos big bags. O efeito dor é relatado como proveniente destas ações. Apenas o grupo responsável pela coleta na rua 
e por conduzir o carrinho com o material coletado é que traz referência a esses riscos, traduzidos pelo resultado das dores no corpo, principalmente, no segmento dos braços, coluna e pernas.

A representação das queixas ergonômicas oriundas do trabalho está associada à satisfação pessoal que também está associada à idade. O grupo com maior idade não refere dor após a jornada de trabalho. A ocorrência da dor parece estar relacionada ao efeito do tipo de tarefa desenvolvida e ao grau de satisfação pessoal na atividade. Apresenta uma relação diretamente proporcional à tarefa e inversamente proporcional à satisfação. No grupo de 18 a 20 anos, responsável pela coleta e condução do carrinho carregado de resíduos sólidos, a dor e o cansaço físico após a jornada de trabalho estão presentes. Já entre os maiores de 47 anos de idade, grupo onde foi observada maior referência à satisfação e realização profissional, o resultado dor relacionada à ocupação está ausente.

Os catadores, maiores de 47 anos, mesmo diante de sobrecarga física sobre o corpo como, levantamento manual de peso, trabalho físico pesado, postura inadequada, repetitividade, trabalho em pé ou de cócoras, torção do tronco e flexão da coluna, ritmo excessivo de trabalho, não referem presença de risco no ambiente da sede da Cooperativa, confirmando a conotação de segurança que envolve este ambiente. Além disso, conclui-se que, em se tratando de uma atividade com alta demanda física, o discurso da negação da dor proveniente do trabalho entre aqueles maiores de 47 anos de idade, remete também a uma negação e não percepção do risco. Sobressai uma postura de superação, difundida entre eles, como requisito necessário ao enfrentamento da atividade laboral e como sinônimo de força. Logo, a percepção deste tipo de risco relacionado à atividade de coleta de materiais recicláveis é tênue e restrita à atividade de coleta.

A ausência de direitos trabalhistas aparece nos discursos como um fator de risco ocupacional. O trabalhador sem garantias, quanto à aposentadoria e desamparado em casos de acidentes ou doenças, se expõe a fortes cargas físicas, por vezes, desconsiderando limites físicos e protelando tratamentos de saúde, em função da busca pelo aumento da lucratividade, diretamente relacionada à quantidade da coleta de materiais reciclados. Estudo de Medeiros e Macedo (2006) também retrata a preocupação dos catadores quanto à ausência de garantias trabalhistas. 
Os catadores percebem a situação de informalidade como um agravante dos riscos vivenciados no dia-a-dia, pois em todas as situações de doenças ocorridas no grupo que resultaram em muitos dias de afastamento, os cooperativados tiveram prejuízos financeiros, decorrentes dos descontos ocorridos devido às faltas e, consequente, redução na coleta. Os relatos exprimem que sem previdência, por vezes, negligenciam a saúde, colocando em primeiro plano a necessidade básica da subsistência, percebendo tal atitude como um fator de risco.

Trabalhar em equipe tem um grande significado nas falas dos catadores, pois o trabalho é eminentemente coletivo e para alcançar os objetivos dependem do esforço e união de todos. A importância dada ao grupo na organização do trabalho também pode ser detectada no estudo de Santos (1990).

As relações de trabalho são caracterizadas por todo o grupo como harmoniosas, colaborativas, confiáveis e respeitosas. Os cooperativados se consideram membros de uma mesma família. Os integrantes se amparam e têm a responsabilidade de se protegerem. Estar em grupo representa segurança. O trabalho em grupo é visto como um fator de proteção, segurança, de prevenção de acidentes, o que tornaria o trabalho mais seguro.

As expressões "uma família", usada para representar os colegas de trabalho, e "casa", indicando o local de trabalho, explicam e ratificam a conotação do aconchego e segurança culturalmente atribuídos ao lar e à família. Percebeu-se que o "trabalho em família" é tido como promissor de segurança, de conforto e tranquilidade. O grupo se ampara e mostra-se solidário. $\mathrm{O}$ trabalho em grupo tem uma representatividade grande e chega a apresentar uma conotação de superpoder, sendo que cada integrante demonstra ser corresponsável pela segurança de todos.

Neste contexto, o trabalhador assume a responsabilidade pela prevenção, por sua saúde e a do grupo, surgindo a autoculpabilização nos casos de acidentes, pois o risco é entendido como controlável, sendo o comportamento cauteloso supostamente suficiente para a prevenção de acidentes.

O enfrentamento do risco com naturalização é difundido entre os mais experientes e está presente durante todo o processo de trabalho. São as informações preventivas centradas na experiência e no bom 
senso do grupo que fortalecem os cooperativados na superação de limites, perigos e dificuldades diárias.

O grupo acredita exercer uma gestão sobre os riscos, principalmente, os relacionados a acidentes perfurocortantes, os mais identificados pelo grupo.

Além disto, o trabalho em equipe, reconhecido como fator de segurança para o grupo, também é admitido como uma forma de enfrentar o risco.

O uso dos equipamentos de proteção individual também é tido como uma forma de enfrentamento da situação percebida como risco. Para o grupo estudado, o uso de equipamentos de proteção individual (EPI) como luvas, botas, máscara, calça e roupas de manga comprida e o cuidado e atenção na realização das atividades estão relacionados à segurança e à prevenção de acidentes. $\mathrm{O}$ equipamento de proteção individual mais utilizado pelo grupo é a luva.

O uso de fardas, o manuseio dos materiais afastados do corpo e a mesa de triagem surgem como medidas de diminuição do risco de contaminação. O contato físico do resíduo sólido com o corpo está no discurso dos catadores como elemento propenso a acidentes e doenças.

Embora os catadores percebam e citem a existência de fatores de risco, não reconhecem suas queixas ou problemas de saúde atuais como ocupacionais. Justificam-nos com outras questões, como idade e doenças prévias. E o risco, em muitos momentos, só transita no imaginário.

Mesmo diante de uma atividade insalubre, o grupo pouco menciona a presença de doenças associadas à catação. Apenas os acidentes perfurocortantes, as quedas e as infecções de pele são associados à ocupação, como também encontrado nos estudos de Ferreira e Anjos (2001), Porto et al. (2004), Miura (2004), Medeiros e Macedo (2006), Cavalcante e Franco (2007).

Com referência às experiências pessoais de doenças ocupacionais, os relatos se direcionam para terceirização, naturalização, negação, minimização e eufemização. Existe uma dificuldade de reconhecer a doença e a dor do momento presente como ocupacionais. Os acidentes, sim, adquirem um caráter real de infortúnio, mas as doenças assumem uma possibilidade abstrata.

Quando questionados sobre acidentes de trabalho, a maioria já sofreu um ou mais acidentes ou doenças consideradas ocupacionais. 
Sexo, escolaridade, idade e tempo de experiência com a coleta não estão associados à ocorrência de acidentes típicos de trabalho. No entanto, as doenças de pele estão associadas ao tempo de exposição com a coleta, ou seja, ao tempo de experiência com este trabalho.

Para os catadores cooperativados, o espaço da sede da Cooperativa tem uma representatividade bastante significativa, principalmente, para os cooperativados com maior tempo de atividade. É notável os sentimentos de amor, orgulho, autoafirmação, esperança e valorização dispensados à Organização. Assinalam este ambiente e os materiais que ali se encontram como seguros, limpos e inofensivos. O potencial de risco dos materiais recicláveis coletados na rua desaparece ao cruzar o portão de acesso da sede da Cooperativa, ao ponto dos cooperativados não distinguirem no lugar a presença de riscos.

\section{Considerações finais}

A percepção de risco dos catadores de materiais recicláveis é diminuída pela necessidade de sobrevivência. $O$ valor recai sobre o material reciclável, que gera rendimento e subsistência, e o risco assume um papel sutil no imaginário.

A primeira menção dada ao risco é relativa aos cortes e perfurações causados pelos materiais perfurocortantes encontrados nos resíduos sólidos, seguidos pelos riscos relacionados ao manuseio de carga, ao trabalho físico pesado, ao uso de força e posturas anômalas do corpo, e a questão da informalidade.

A respeito da exposição ocupacional, diante das circunstâncias e resíduos desconhecidos, não foi observado nos catadores estudados da Cooperativa um sentimento de preocupação, medo, ou antecipação. As possíveis consequências adversas são ignoradas, as percepções do risco costumam acontecer no cotidiano e após exposições com consequências deletérias sobre o corpo. Diante de situações nunca antes vividas, que promoveram repercussões desagradáveis, comunicam os eventos adversos aos demais para que esta exposição possa ser evitada.

Apenas os riscos palpáveis e visíveis são percebidos e referidos. Aquilo que pode ser visto e sentido como os cortes, as infecções de pele, as substâncias em pó são, facilmente, percebidos e identificados como riscos ocupacionais. 
Quando o risco é percebido como uma realidade, o modo de enfrentamento é a ação com cuidado, cautela, atenção e coragem. A prevenção de riscos está intimamente relacionada ao trabalho com alto nível de atenção que é difundido como sinônimo de proteção. A atenção de todo o grupo tem o poder de protegê-los, surgindo uma ideologia defensiva.

O risco percebido só é encarado quando acreditam nos benefícios compensatórios de tais exposições e quando o controle dos processos permite que a gestão seja facilitada, transformando no subconsciente uma atividade considerada inicialmente perigosa em inofensiva.

A percepção de risco está associada à proximidade do evento para os mais vulneráveis. Aqueles que trabalham diretamente com a coleta seletiva no território da rua são os que referem perceber os riscos de acidentes de trabalho, cortes, infecções por substâncias como pós de alumínio, de serra e de vidro, queda, sobrecarga de trabalho, levantamento de peso e risco de acidentes de trânsito e com o carrinho de transporte do material coletado.

O significado de trabalho para o grupo é equivalente à saúde e a negação da doença é prova de força. Associar trabalho à doença não é frequente entre o grupo. É como se o trabalho só gerasse benefícios. E quando mencionam, é comum o relato ser na terceira pessoa e no tempo passado como se o problema já superado não lhes pertencesse. As marcas e cicatrizes são demonstradas como "troféus" que registram superação e são provas de que tantos caminhos já foram percorridos, garantindo o sentimento de posse pela Cooperativa e pelas conquistas alcançadas.

O corpo dos cooperativados é um instrumento de trabalho e perceber este corpo como "sadio" torna-se essencial para garantia, inclusive, de sua permanência na Cooperativa. Sem amparos sociais, como o da Previdência Social, os catadores temem que, sem sua própria força de trabalho, representada pela autoafirmação da saúde e negação das queixas atuais como ocupacionais, sejam considerados rejeitos e, assim, como os resíduos sólidos, sejam desprezados.

No estudo da percepção do risco no ambiente e no processo de trabalho, existiu uma polarização risco/benefício, aceitação/negação, medo/enfrentamento. Aqueles riscos altamente perceptíveis, aceitos e difundidos pelos mais experientes, como os acidentes perfurocortantes 
e as doenças de pele, surgem nos discursos e nas histórias de vida. São considerados inevitáveis, enfrentados diariamente.

Os catadores que permanecem no ambiente supostamente seguro da sede da Cooperativa não costumam referir riscos. Provavelmente, este "silêncio" não represente impessoalidade, mas sim, uma condição de distanciamento e de proteção, já que o enfrentamento do risco é tido como inevitável, tornando-se, portanto, desnecessário ratificá-lo.

A gestão participativa, a autonomia e o trabalho em grupo representam uma valorização do trabalho de coleta de materiais recicláveis, ofuscam a informalidade e trazem o sentimento de profissionalização e emancipação para esta classe profissional.

A negação do risco é observável e a superação das dificuldades faz-se necessária em uma situação de instabilidade financeira, na qual o único meio de gerir recursos financeiros é uma maior quantidade de materiais recicláveis coletados. A relação de negação e minimização do risco, consolidada coletivamente, ocorre a partir da necessidade de sobrevivência do catador e de sua família.

Mesmo diante de todas as dificuldades enfrentadas - como baixo rendimento, falta de insumos, exposição a riscos, sobrecarga de trabalho - sentem-se motivados a continuar equacionando e superando tais questões na esperança de dias melhores, traduzidos como aumento do rendimento, acesso a insumos e garantias sociais, a exemplo da Previdência Social. Entre eles, é marcante a projeção otimista em relação ao futuro, pois acreditam que a articulação com os poderes públicos lhes garantirá, um dia, condições dignas de trabalho.

A percepção de risco ocupacional entre catadores de materiais recicláveis revela que o essencial para a melhoria de vida e trabalho destes trabalhadores, não se resume à implantação de medidas de educação em saúde que sensibilize sobre a percepção de riscos ocupacionais, mas, sobretudo, o que importa é a adoção de políticas públicas e medidas individuais que viabilizem a garantia de acesso a direitos sociais, trabalhistas, melhores condições de subsistência, além de uma ampla discussão sobre riscos sob a ótica do trabalhador, fundamental para o sucesso destas ações. A recomendação de outros estudos sobre riscos ocupacionais sob o "ponto de vista" do trabalhador faz-se importante para instrumentalizar as políticas públicas, com o fim de promover dignidade e segurança no trabalho. 


\section{Referências}

ADAMETES, C. M. O olhar da inclusão: possibilidades de pesquisa com uma catadora de lixo. 1998. 149f. Dissertação (Mestrado em Sociologia) Universidade Estadual Paulista Júlio de Mesquita Filho, Araraquara, São Paulo, 1998.

ALMEIDA, J. R; ELIAS, E. T; MAGALHÃES, M. A. Efeito da idade sobre a qualidade de vida e saúde dos catadores de materiais recicláveis de uma associação em Governador Valadares, Minas Gerais, Brasil.

Ciência \& Saúde Coletiva, v. 14, n. 6, p. 2169-2180, 2009.

AYRES, J. R. C. M. et al. Vulnerabilidade e prevenção em tempos de AIDS. In: BARBOSA, R. M. ; PARKER, R. (Orgs. ). Sexualidade pelo avesso: direitos, identidades e poder. São Paulo: Editora 34, 1999. p. 49-72.

BRASIL. Ministério do Meio Ambiente. Lei no 12. 305, de 02 de agosto 2010, institui a Política Nacional de Resíduos Sólidos e dá outras providências. Diário Oficial da União, Brasília, 03 ago. 2010.

. Ministério do Trabalho e Emprego. Portaria no 397, de 09 de outubro de 2002. Aprova a Classificação Brasileira de Ocupações - CBO. Diário Oficial da União, Brasília, 10 out. 2002.

. Ministério do Trabalho e Emprego. Classificação Brasileira

de Ocupações. 2002. Disponível em: < http://www.mtecbo.gov.br/ busca/descricao.asp?codigo=5192-05> . Acesso em: 01 abr. 2009.

. Ministério da Saúde. Conselho Nacional de Saúde, Resolução no 196 de 10 de outubro de 1996. Aprova as diretrizes e normas regulamentadoras de pesquisas envolvendo seres humanos. Diário Oficial da União. Brasília, out. 1996.

CARMO, S. A semântica do lixo e o desenvolvimento socioeconômico dos catadores de recicláveis: considerações sobre um estudo de caso múltiplo em cooperativas na cidade do Rio de Janeiro.

Caderno EBAPE. BR, v. 7, n. 4, p. 591-606, 2009.

CAVALCANTE, S. ; FRANCO, M. F. A. Profissão perigo: percepção de risco à saúde entre os catadores do lixão do Jangurussu. Revista Malestar e Subjetividade, Fortaleza, v. 7, n. 1, p. 211-231, 2007.

CRUZ NETO, O. ; MOREIRA, M. R. ; SUCENA, L. F. M. Grupos focais e pesquisa social qualitativa: o debate orientado como técnica de investigação. In: ENCONTRO da Associação Brasileira de Estudos Populacionais. Ouro Preto - MG. 13 abr. 2002. Disponível em: <www.dppg.cefetmg. br/mtp/TecnicadeGruposFocaisdoc > . Acesso em: 15 abr. 2011. 
DEJOURS, C. A loucura do trabalho. São Paulo: Cortez Editora, 1992.

FERREIRA, J. A. ; ANJOS, L. A. Aspectos de saúde coletiva e ocupacional associados à gestão dos resíduos sólidos municipais.

Caderno Saúde Pública. v. 17, n. 3, p. 689-696, 2001.

FRASSON, C. B. Análise do discurso: considerações básicas, 2007. In: Cadernos da Funcamp, v. 6, n. 6, 2007.

GONÇALVES, R. Catadores de materiais recicláveis: trabalhadores fundamentais na cadeia de reciclagem do país. Serviço Social e Sociedade, v. 82, n. 65, p. 87-109, 2005.

GONÇALVES, H. H; ABEGÃO, L. H. Da ausência do trabalho à viração: a importância da catação na manutenção da vida. In: Encontro da ANNPAS, II, 2004, Anais... Indaiatuba, São Paulo. Disponível em: <http: \\www.anppas.org.br/encontro/segundo/ Papers/GT/GT09/HeloisaeLuis.pdf>. Acesso em: 23 abr. 2009.

JACOBI, P. Sustentabilidade ambiental, consumo e cidadania. Ambient. Soc. [online], v. 9, n. 1, p. 183-186, 2006.

JASANOFF, $S$. The political science of risk perception. Reliability Engineering \& System Safety, n. 59, p. 91-99, 1998.

JOIA, P. R; SILVA, M. S. F. Sistema de coleta seletiva dos resíduos sólidos domiciliares produzidos na cidade de Aquidauana. In: SIMPÓSIO sobre Recursos Naturais e Sócio-econômicos do Pantanal, 2004, CORUMBÁ-MS. Anais. . Corumbá: EMBRAPA, 2004.

JUNCÁ, D. C. de M. Mais que sobras e sobrantes: trajetórias de sujeitos no lixo, 2004. 250f. Tese (Doutorado em Saúde Pública) Escola Nacional de Saúde Pública, Fundação Oswaldo Cruz, Rio de Janeiro, 2004.

LIMA, M. L. Factores sociais na percepção de riscos. Revista da Associação Portuguesa de Psicologia, v. 12, p. 11-28, 1998.

MEDEIROS, L. F. R. ; MACEDO, K. B. Catador de material reciclável: uma profissão para além da sobrevivência?

Psicologia \& Sociedade, v. 18, p. 62-71, 2006.

MINAYO, M. C. de S. O desafio do conhecimento: pesquisa qualitativa em saúde. 8. ed. São Paulo: Hucitec, 2007.

MIURA, P. C. O. Tornar-se catador: uma análise psicossocial. 2004. 134f. Dissertação (Mestrado em Psicologia Social) - Pontifícia Universidade Católica de São Paulo, São Paulo, 2004.

MORAES, L. R. S. Acondicionamento e coleta de resíduos sólidos domiciliares e impactos na saúde de crianças residentes em 
assentamentos periurbanos de Salvador, Bahia, Brasil. Cadernos de Saúde Pública, Rio de Janeiro, n. 23, p. 643-649, 2007.

MORAES, T. et al. Da norma ao risco: transformações na produção de subjetividades contemporâneas. Psicologia em estudo, n. 1, p. 91-102, 2002.

NAVARRO, M. V. T. Conceito e controle de riscos a saúde em radiodiagnóstico: uma abordagem de vigilância sanitária. 2007. 182f. Tese (Doutorado em Saúde Coletiva) - Instituto de Saúde Coletiva, Universidade Federal da Bahia, Salvador, 2007.

NOYES, J. Designing for humans. Hove (East Sussex), Psychology Press, 2001.

OLIVEIRA, D. A. M. Percepção de Riscos Ocupacionais em Catadores de Materiais Recicláveis: Estudo em uma Cooperativa em Salvador-Bahia. 2011. 176f. Dissertação (Mestrado em Saúde, Ambiente e Trabalho) - Faculdade de Medicina da Bahia, Universidade Federal da Bahia, Salvador, 2011.

ORLANDI, E. P. Análise de discurso: princípios e fundamentos. 8. ed. Campinas, SP: Pontes, 2009.

POESCHL, G. Representações das diferenças entre os sexos, práticas familiares e relações entre homens e mulheres. Revista Estudos. Goiânia: UCG, v. 30, n. 1, p. 31-49, 2003.

PORTO, M. et al. Lixo, trabalho e saúde: um estudo de caso com catadores em um aterro metropolitano no Rio de Janeiro. Cadernos de Saúde Coletiva, v. 20, p. 1503-1514, 2004.

SANDERS, M. S. ; McCORMICK, E. J. Human error, accidents, and safety. In: . Human Factors in Engineering and Design. 7. ed. New York: McGraw-Hill, 1993. p. 655 - 695.

SANTOS, J. B. F. As condições de trabalho e as suas repercussões na vida e na saúde dos catadores de lixo do aterro sanitário do Jangurussu: relatório de pesquisa. Fortaleza, CE: SINE/CE, 1990.

SINGER, P. As grandes questões do trabalho no Brasil e a economia solidária. Proposta, Rio de Janeiro, Fase, n. 97, jun. /ago. 2003.

SIQUEIRA, M. M; MORAES, M. S. Saúde coletiva, resíduos sólidos urbanos e os catadores de lixo. Ciência saúde coletiva, v. 14, n. 6, p. 2115-2122, 2009.

VELLOSO, M. P; SANTOS. E. M; ANJOS, L. A. Processo de trabalho e acidentes de trabalho em coletores de lixo domiciliar na cidade de Rio de Janeiro. Caderno de Saúde Pública, Rio de Janeiro, v. 13, p. 603-700, 1997. 